\title{
http:// bjas.bu.edu.eg \\ Effect Of Av Shunt On Cardiac Function in Patient with Fair Systolic Function
}

A.M.Mohamed, S.M.Ammar, M.M.Ali andW.M.Tawfik

Cardiology Dept, Faculty of Medicine, Benha Univ,Benha, Egypt

E-Mail: Dr.hamouda50@gmail.com

\begin{abstract}
Cardiovascular disease is the leading cause of the death in patients receiving chronic renal replacement therapy, Arteriovenous fistulas [AVFs] have superior longevity, lower infection and mortality rates and are associated with lower cost, and hence have become the vascular access of choice for patients needing dialysis. The aim of this study is to assess the effect of AVF on cardiac function in patients with fair systolic function in patients with ESRD .This is a prospective ,non-controlled, observational study that will include 20 patients who will been admitted to Heliopolis Hospital with ESRD and treated with hemodialysis and cardiac function will be assessed by echocardiography preoperative of AVF creation and 3 months postoperative There was statistically significant difference in diastolic dysfunction grades between before and after AVF. there is an effect of AVF on cardiac function in patients with fair systolic function in patients with ESRD as there was statistically significant difference in diastolic dysfunction grades between before and after AVF.
\end{abstract}

Keywords: AVF, Cardiovascular disease, ESRD.

\section{Introduction}

Hemodialysis [HDx] stays those foundation about renal substitution cost treatment for end-stage renal disappointment [ESRF] patients overall. Then again its formation need An number from claiming unfriendly hemodynamic results. Instantly taking after creation, arteriovenous fistula $[\mathrm{AVF}]$ will be connected with an expand to heart yield [CO], attained predominantly through a decrease On systemic vascular resistance, expanded myocardial contractility, What's more a expansion to stroke volume [SV] What's more heart rate[1,2]. These alterations need aid connected with early increments clinched alongside left ventricular [LV] filling weight with those possibility for resultant sway for atrial and ventricular chamber measurements Also capacity.

To uphold addition systemic perfusion, co must increment proportionately, bringing about longer-term suggestions to cardiovascular Furthermore vascular structure Also work [2,3]. Historically, AVF-creation need been connected with intensifying from claiming $\mathrm{lv}$ hypertrophy Furthermore resultant diastolic brokenness Furthermore exited atrial dilatation[4]. In a few patients, a monster AVF might prompt progressive high-output cardiovascular failure, notwithstanding safeguarded $\mathrm{lv}$ systolic capacity[5,6]. To date, large portions of the investigations assessing the cardiovascular [CV] impacts for AVF have utilized an echocar $\neg$ diographic procedure.

Cardiovascular malady will be the heading reason for those deathin patients getting constant renal substitution cost therapy[1,2] arteriovenous fistulas [AVFs] have predominant longevity, lowerinfection and mortal sin rates What's more need aid connected with lowercost, and henceforth have turn into the vascular get from claiming decision forpatients expecting dialysis. Notwithstanding their cooperation with An lowermortality, AVFs have critical impacts for cardiovascular functionspredominantly identified with the build for preload Also cardiacoutput [CO].

Congestive heart disappointment [CHF] may be Exceedingly pervasive amongpatients with ESRD. Give or take $35-40 \%$ of patients withESRD have a made CHF finding In start ofhemodialysis. [7,8 and 9] Patients for
ESRD Furthermore CHF bring a farworse prognosis over the individuals without CHF [10]. Since hemodynamic streamlining is those corner stone about Dealing with patientswith ESRD and in addition the individuals with $\mathrm{CHF}$, concentrating on the hemodynamiceffects from claiming AVFs over patients for ESRD for and withoutCHF is An sensible errand.

Those sway from claiming these physiological impacts of AVF on the cardiacfunction will be dubious. Same time a significant number investigations suggestedthat those diminished vascular safety and the expanded COare predisposing variables for those advancement alternately the worseningof heart failure, [ 7]others suggester that those decline On peripheralresistance Furthermore pulse for a parallel expand inejection portion Might make possibly valuable [11]. Despite A percentage creators postulate that cardiovascular decompensationin ESRD patients for AVFs happens main Previously, people withpreviously built constant heart disease, there is evidencethat AVF formation may be An major hazard figure to Creating An newonset CHF [ 4,12, 13 and 14], in the HEMO study, indications of $\mathrm{CHF}$ developedde novo Throughout dialysis treatment Previously, $17 \%$ of the patients. Albeit this Might be purely because of the helter skelter predominance about riskfactors to Creating CHF in the ESRD population, a independenteffect from claiming AVFs need been proposed.

\section{Subjects and methods}

\subsection{Study design}

This is a prospective, non -controlled, observational study that will include 20 patients who will been admitted to Heliopolis Hospital with ESRD and treated with hemodialysis and cardiac function will be assessed by echocardiography preoperative of AVF creation and 3 months postoperative.

\subsection{Ethical Considerations}

Approval was taken from the Ethics Committee of Helliopoles Hospital, aim of the study explained to the patients also the privacy of data secured . 


\subsection{Inclusion criteria}

Patients with ESRD candidate for AVF creation. Fair systolic function $[\mathrm{EF} \approx 40-50 \%$ ].

\subsection{Exclusion criteria}

Impaired systolic function $[<40 \%]$. - Ischemic heart disease. - Significant valvular heart disease. - Patients with previous AVF

All the patients will be subjected to:

- Full history taking: - Age - sex - risk factors

- examination : - Blood pressure - Pulse Cardiac examination - Chest examination

- Echocardiographic data: full echocardiographic parameters including: - Dimesions - Valves Ejection Fraction using [ M-Mode \& Simpson method ]

Images from standard views, including the parasternal long axis, short axis at the papillary muscle level, and apical 4 chamber and 2 chamber views were recorded, then left ventricular ejection fraction was estimated by two Dimensional echocardiography and MMode and Modified simpson method as well as left ventricular diastolic function parameters such deceleration time [DT] $[\mathrm{ms}]$, peak transmitral early diastolic flow velocity [E wave], peak transmitral late diastolic flow velocity [A wave], mitral E/A ratio .

\subsection{Study end point}

- $\quad$ 1ry end point : Change in ejection fraction after the shunt

- $2 r y$ end point : Change in the clinical symptoms of the patients includes :

Heart failure: inability of the heart to keep up with the demands on it and failure of the heart to pump blood with normal efficiency and the heart is unable to provide adequate blood flow to the organs

Arrhythmia : any type of arrhythmia either tachyarrhthmia or bradyarrhythmia .

\subsection{Statistical analysis}

Table (1) Baseline characteristics of the studied group
All data were collected, tabulated and statistically analyzed using SPSS version 19. Continuous Quantitative variables were expressed as the mean \pm SD and categorical qualitative variables were expressed as absolute frequencies [number]\& relative frequencies [percentage]. Continuous data were checked for normality by using Shapiro Walk test. Paired t-test was used to compare two related groups of normally distributed data.

Paired categorical data were compared using sign test. All tests were two sided. p-value $<0.05$ was considered statistically significant [S], p-value $<0.001$ was considered highly statistically significant [HS], and p-value $\geq 0.05$ was considered statistically insignificant [NS].

\section{Results}

Table (1) Age of the studied participants ranged between 25 and 67 years with mean of 49 years. Near three fourth of them were males [70\%], more than half of them had diabetes mellitus and hypertension [60\% and $70 \%$ respectively]. Only $10 \%$ of them had RWMA.Table (2) HS: highly significant difference $[<0.001]$. NS: nonsignificant difference [p>0.05]. Table (3) highly statistically significant differences in both LA, LVEDd and LVEDs parameters between before and after AVF which were found to be significantly higher in after doing AVF when compared to before it [4.92, 5.65 and 4.42 versus $4.73,5.47$ and 4.28 respectively]. Table (4) statistically significant difference in ejection fraction between before and after AVF which was found to be significantly higher in after doing AVF when compared to before it [ 45.8 versus 44.3 respectively] Table (5) nonstatistically significant difference in chest findings between before and after AVF. It was noticed that all cases return to clear chest findings after doing AVF. Table (6) non-statistically significant difference in cardiac findings between before and after AVF Table (7) non-statistically significant difference in valves conditions between before and after AVF. Table (8) was statistically significant difference in diastolic dysfunction grades between before and after AVF.

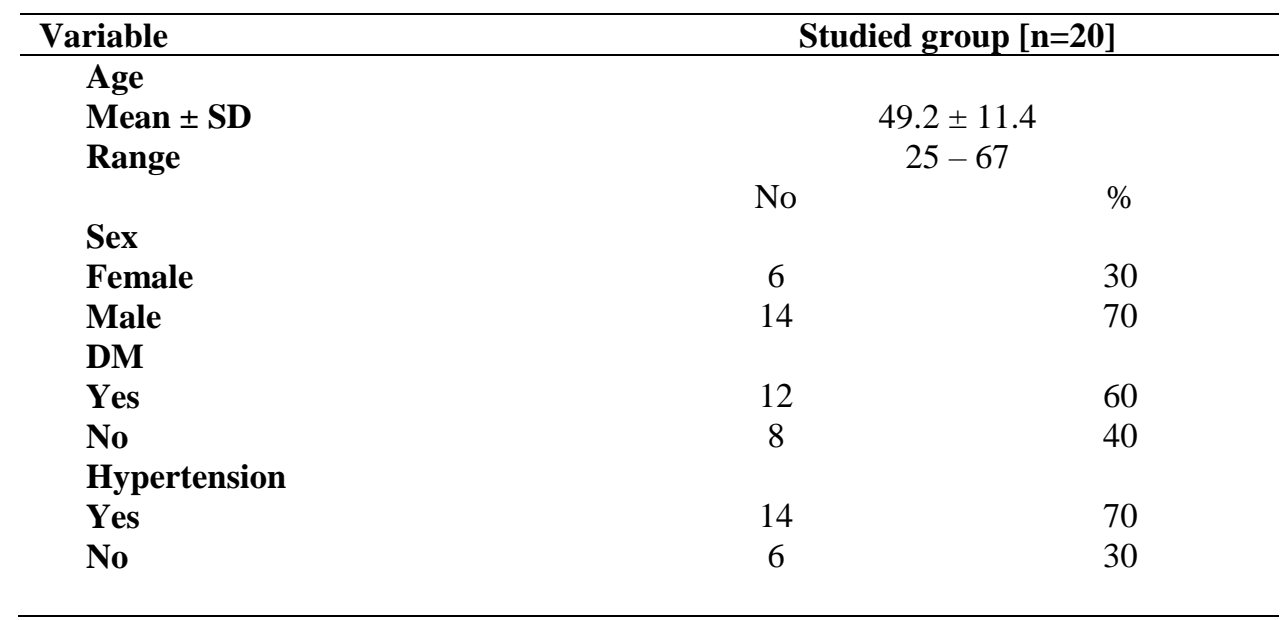


Table (1) Continue

Ischemic heart disease

No

RWMA

18

90

210

Table (2) Relation between before and after intervention as regarding blood pressure and pulse among the studied group.

\begin{tabular}{lccc}
\hline Variable & N. & Mean & p-value \\
\hline $\begin{array}{l}\text { Systolic B.P } \\
\text { Before }\end{array}$ & 20 & 153.7 & $<0.001$ \\
$\begin{array}{l}\text { After } \\
\text { Diastolic B.P }\end{array}$ & 20 & 141.7 & {$[\mathrm{HS}]$} \\
$\begin{array}{l}\text { Before } \\
\text { After }\end{array}$ & 20 & 91.2 & $<0.001$ \\
Pulse & 20 & 84.5 & {$[\mathrm{HS}]$} \\
Before & & & \\
After & 20 & 75.3 & 0.360 \\
& 20 & 77.2 & {$[\mathrm{NS}]$} \\
\hline
\end{tabular}

Table (3) Relation between before and after intervention as regarding ECHO parameters among the studied group

\begin{tabular}{lccc}
\hline Variable & N. & Mean & p-value \\
\hline LA & & & \\
Before & 20 & 4.73 & $<0.001$ \\
After & 20 & 4.92 & $(\mathrm{HS})$ \\
$\begin{array}{l}\text { IVSD } \\
\text { Before }\end{array}$ & 20 & 0.99 & 1.00 \\
After & 20 & 0.99 & $(\mathrm{NS})$ \\
PWDD & & & \\
Before & 20 & 0.99 & 0.330 \\
After & 20 & 1.00 & $(\mathrm{NS})$ \\
LVEDD & & & \\
Before & 20 & 5.47 & $<0.001$ \\
After & 20 & 5.65 & $(\mathrm{HS})$ \\
LVEDS & & & \\
Before & 20 & 4.28 & $(\mathrm{~S})$ \\
After & 20 & 4.42 & \\
\hline
\end{tabular}

Table (4) Relation between before and after intervention as regarding EF among the studied group

\begin{tabular}{lccc}
\hline Variable & N. & Mean & p-value \\
\hline EF & & & \\
Before & 20 & 44.3 & 0.009 \\
After & 20 & 45.8 & $(\mathrm{~S})$ \\
\hline
\end{tabular}

Table (5) Chest examination before and after intervention among the studied group

\begin{tabular}{lccccc}
\hline \multirow{2}{*}{ Variable } & $\begin{array}{c}\text { Chest exam before } \\
(\mathbf{n = 2 0})\end{array}$ & \multicolumn{2}{c}{$\begin{array}{c}\text { Chest exam after } \\
(\mathbf{n = 2 0})\end{array}$} & \multirow{2}{*}{$\mathbf{P}$} \\
\cline { 2 - 5 } & No & \% & No & \% & \\
\hline Chest findings & & & & 0 & \\
Basal crepitations & 5 & 25 & 0 & 0.527 \\
Clear & 13 & 65 & 20 & 100 & $($ NS) \\
Wheezes & 1 & 5 & 0 & 0 & 0 \\
Coarse crepitation & 1 & 5 & 0 & 0 \\
\hline
\end{tabular}


Table (6) Cardiac examination before and after intervention among the studied group

\begin{tabular}{|c|c|c|c|c|c|}
\hline \multirow[t]{2}{*}{ Variable } & \multicolumn{2}{|c|}{$\begin{array}{l}\text { Cardiac exam } \\
\text { before }(n=20)\end{array}$} & \multicolumn{2}{|c|}{$\begin{array}{l}\text { Cardiac exam } \\
\text { after }(n=20)\end{array}$} & \multirow[t]{2}{*}{$\mathbf{P}$} \\
\hline & No & $\%$ & No & $\%$ & \\
\hline \multicolumn{6}{|l|}{$\begin{array}{l}\text { Cardiac findings } \\
\text { S1-S2 }\end{array}$} \\
\hline S1-S2-S3 & 11 & 55 & 11 & 55 & 0.655 \\
\hline systolic & 3 & 15 & 2 & 10 & (NS) \\
\hline murmur on apex & 6 & 30 & 7 & 35 & \\
\hline
\end{tabular}

Table (7) Valves examination before and after intervention among the studied group

\begin{tabular}{|c|c|c|c|c|c|}
\hline \multirow[t]{2}{*}{ Variable } & \multicolumn{2}{|c|}{$\begin{array}{c}\text { Cardiac exam before } \\
(\mathbf{n}=20)\end{array}$} & \multicolumn{2}{|c|}{$\begin{array}{l}\text { Cardiac exam after } \\
(n=20)\end{array}$} & \multirow[t]{2}{*}{$\mathbf{P}$} \\
\hline & No & $\%$ & No & $\%$ & \\
\hline \multicolumn{6}{|l|}{ Valves } \\
\hline Mild MR & 8 & 40 & 9 & 45 & \\
\hline Mild AR & 1 & 5 & 1 & 5 & \\
\hline Moderate MR & 6 & 30 & 5 & 25 & \\
\hline Moderate MR, mild AR & 1 & 5 & 0 & 0 & 0.750 \\
\hline Trivial MR & & & & & (NS) \\
\hline Moderate MR, Moderate & 4 & 20 & 2 & 10 & \\
\hline $\mathbf{A R}$ & 0 & 0 & 1 & 5 & \\
\hline \multicolumn{6}{|l|}{ Moderate to severe MR } \\
\hline \multirow[t]{2}{*}{ Severe MR } & 0 & 0 & 1 & 5 & \\
\hline & 0 & 0 & 1 & 5 & \\
\hline
\end{tabular}

Table (8) Diastolic dysfunction before and after intervention among the studied group

\begin{tabular}{lccccc}
\hline Variable & \multicolumn{2}{c}{$\begin{array}{c}\text { Dysfunction } \\
\text { before }(\mathbf{n = 2 0})\end{array}$} & $\begin{array}{c}\text { Dysfunction after } \\
(\mathbf{n = 2 0})\end{array}$ & \multirow{2}{*}{$\mathbf{P}$} \\
\cline { 2 - 5 } & No & $\mathbf{\%}$ & No & \% & \\
\hline Dysfunction & 13 & 65 & 5 & 25 & \\
Grade I & 6 & 30 & 12 & 60 & 0.002 \\
Grade II & 1 & 5 & 3 & 15 & [S] \\
Grade III & & & & & \\
\hline
\end{tabular}

\section{Discussion}

Those study included 20 patients evaluated Eventually Tom's perusing echocardiography preoperative for AVF What's more 3 months after AVF production.

The sum subjects were assessed Toward history taking[ period, sex, danger figures ], clinical examination including [ pulse, heart rate , midsection examination, cardiovascular examination ]. Our examine indicated that there were Exceedingly statistically huge contrasts clinched alongside both systolic Also diastolic pulse between previously, then then afterward AVF which were discovered will make altogether more level over then afterward completing AVF when contrasted with When it $[141.7,84.5$ versus 153.7 What's more 91. 2 respectively]. However, those Contrast the middle of previously, then then afterward mediation might have been non-significant Similarly as in regards pulse.

Same time On [15] contemplate also demonstrated that diastolic What's more systolic pulse diminished altogether times 7 and 14 following av fitula formation.
In Yogesh n. V. Reddy, et al. 2017 consider described chronic, longitudinal progressions On cardiovascular structure Also capacity to patients for ESRD following those surgical creation of a AVF/AVG for haemodialysis get. Accompanying AVF, there were huge diminishments On blood vessel blood weight.

In our investigation those Contrast between previously, then then afterward mediation might have been non-significant as in regards pulse.

Same time On investigation indicated that heart rate expanded by a normal for $5 \mathrm{bpm}[\mathrm{P}=0$. 003]. In our ponder indicates that there were Exceedingly statistically noteworthy contrasts in both LA, LVEDd and LVEDs parameters between previously, then then afterward AVF which were discovered to make altogether higher clinched alongside following completing AVF The point when contrasted with in the recent past it $[4.92,5.65$ and 4. 42 versus 4. 73, 5. 47 Furthermore 4. 28 respectively]. However, those distinction between previously, then then afterward intercession might have 
been non-significant Concerning illustration in regards both IVSD Also PWDD.

Done indicated that, $\mathrm{AVF} / \mathrm{AVG}$ formation might have been connected with huge dilatation in the left chamber Furthermore rwanda, changes that were connected with the advancement from claiming episode hezekiah What's more expanded danger for passing.

Previously, [15] consider demonstrated that chap expanded significantly times 7 Furthermore 14 then afterward AVF formation. A significant increment in LVEDd might have been watched days 3 on 14 after those operation, yet all the LVEDs might have been not modified.

Over comparative ponder indicated that echocardiographic parameters for both consider aggregations the HFA gathering exhibited An critical build Previously, lv measurements, volumes, la volume list, lv impostor list.

On our examine reveals to that there might have been statistically huge distinction in launch portion the middle of previously, then after AVF which might have been found with a chance to be fundamentally higher Previously, after completing AVF At contrasted with When it [45. 8 versus 44.3 respectively].

What's more clinched alongside [15] study demonstrated that formation of the av fistula generated all the a significant expand to FS and co then afterward 3 on 14 days. Maximal expands On these parameters concerning lv systolic work were acquired day 7 [FS, $8 \%$; $\mathrm{CO}, 15 \%]$.

Same time done consider indicated that there might have been An slight diminishment On lv systolic capacity, prove by abatements for lv EF.

On comparable study demonstrated that, huge diminishing over launch portion LVEF, and the HFA one assembly needed fundamentally expand On lv fillingpressure, HFA bunch for patients exhibited An significantly bring down launch portion for An mean quality about 57. 32\% Likewise contrasted with $62.90 \%$ to the non-HFA one assembly.

Done vicinity for $\mathrm{HF}$, the choice for a intercession to decrease the AVF Qa if be underpinned via beneficial control about other possibility danger figures referred to on precipitate the infection For example, anemia, hypertension, overabundance inter-dialyticweight addition including a fluid volume over-burden.

Lf clinical indications about hezekiah [e. G. Anxiety prompted or resting dysnea, orthopnea, asthenia,andoedma] persist, then a mediation methodology with right anAVF for persistently helter skelter Qa [22000] ought make embraced.

Clinched alongside our contemplate indicated diastolic brokenness previously, then following intercession "around those concentrated on gathering reveals to that there might have been statistically huge distinction done diastolic brokenness evaluations the middle of previously, then then afterward AVF.

What's more in comparable ponder indicated the HFA one assembly needed fundamentally progress Previously, E/A proportion [denoting higher lv filling weight ].
And clinched alongside [15] contemplate indicated that $\mathrm{lv}$ diastolic capacity with lv inflow profiles, those crest speed from claiming e wave expanded days 3 with 14 then afterward making of the AV fistula, and that of the a wave expanded significantly best day 7 . An timerelated increment Previously, E-A proportion might have been watched $18 \%$ day 14 .

Same time for investigation indicated that there might have been no change for lv diastolic capacity.

What's more for consider indicated that diastolic filling parameters [E should An ratio] were also impaired, characteristic from claiming intensifying diastolic works.

In our examine demonstrated that there might have been statistically critical distinction done pulmonary hypertension between previously, then after AVF.

Also Previously, examine indicated that the HFA assembly needed fundamentally increment SPAP as compared with non-HFA aggregation.

Same time over reveals to build over systolic pulmonary conduit weight over patients accepting hemodialysis with spiral What's more brachial AVFs.

\section{References}

[1] A.C.Guyton, K.Sagawa and Y.Iwashima, Compensations of cardiac output and other circulatory functions in areflex dogs with large A-V fistulas. Am J, vol 40[5], pp 974-982,2002.

[2] Y.Ori, A.Korzets and M.Katz, Haemodialysisarteriovenous access - a prospective haemodynamic evaluation. Nephrol Dial Transplant. Vol 11[1], pp 94-97,1996.

[3] C.Basile, C.Lomonte and L.Vernaglione, The relationship between the flow of arteriovenous fistula and cardiac output in haemodialysispatients.Nephrol Dial Transplant, vol 23[1], pp 282-287,2008.

[4] Y.Ori, A.Korzets and M.Katz, The contribution of an arteriovenous access for hemodialysis to left ventricular hypertrophy. Am J Kidney Dis., vol 40[4], pp 745-752,2002.

[5] C.B.Anderson, J.R.Codd and R.A.Graff:Cardiac failure and upper extremity arteriovenous dialysis fistulas. Case reports and a review of the literature. Arch Intern Med,vol 136[3], pp 292-297,1976.

[6] J.M.MacRae, S.Pandeya and D.P.Humen:Arteriovenous fistula-associated highoutput cardiac failure:a review of mechanisms. Am J Kidney Dis., vol43:e17-22.5, pp323-6, 2004.

[7] A.Levin and R.N.Foley. Cardiovascular disease in chronic renalinsufficiency. Am J Kidney Dis.,vol 36, pp S24-30, 2000.

[8] A.K.Cheung, M.J.Sarnak and G.Yan, Cardiac diseases in maintenance hemodialysispatients: results of the HEMO Study. Kidney Int, vol65, pp2380-9,2004.

[9] A.G.Stack and W.E.Bloembergen. A cross-sectional study of theprevalence and clinical correlates of congestive heart failureamong incident US dialysis 
patients. Am J Kidney Dis, vol38, pp992$1000,2001$.

[10] Cheung AK, Sarnak MJ and Yan G, et al. Cardiac diseases in maintenance hemodialysispatients: results of the HEMO Study. Kidney Int., Vol.65, pp.2380-9, 2004.

[11] S.Korsheed, M.T.Eldehni and S.G.John: Effects of arteriovenous fistula formation on arterial stiffnessand cardiovascular performance and function. NephrolDialTransplant, vol26, pp3296302,2011 .

[12] I.Engelberts, J.H.Tordoir and E.S.Boon:Highoutputcardiac failure due to excessive shunting in a hemodialysisaccess fistula: an easily overlooked diagnosis. Am J Nephrol, vol32, pp.207,1995.
[13] J.M.MacRae, S.Pandeya and D.P.Humen: Arteriovenous fistula-associated high-output cardiac failure:a review of mechanisms. Am J Kidney Dis. ,vol 43:e17-22.5, pp323-6,2004.

[14] R.Martinez-Gallardo, F.Ferreira-Morong and G.Garcia-Pino: Congestiveheart failure in patients with advanced chronic kidneydisease: association with pre-emptive vascular accessplacement. Nefrologia ,vol .32, pp206-12,2012.

[15] Y. Iwashima, T. Horio and Y. Takami: Effects of the creation of arteriovenous fistula for hemodialysis on cardiac function and natriuretic peptide levels in CRF Am J Kidney Dis , vol. 40, pp. 974-982,2002. 